\title{
Current Status of Knowledge and Attitude toward STI Prevention among Out-of-school Youth in the Philippines
}

\author{
Mariko Gunchi ${ }^{1}$, Yuko Tanaka ${ }^{2}$, Maria Teresa Reyes Tuliao ${ }^{3}$, \\ Geraldine Ordonez ${ }^{3}$, Elsi Dwi Hapsari ${ }^{1,4}$, Hiroya Matsuo ${ }^{1, *}$ \\ Department of International Health, Graduate School of Health Sciences, Kobe University, Japan \\ ${ }^{2}$ Department of School Health Sciences, Faculty of Medicine, Graduate School, Tokushima University, Japan \\ ${ }^{3}$ Department of Muntinlupa Health, Centennial Avenue, Laguerta, Tunasan, Muntinlupa City, Philippines \\ ${ }^{4}$ Department of Pediatric and Maternity Nursing, Faculty of Medicine, Public Health, and Nursing, Universitas Gadjah Mada, \\ Yogyakarta, Indonesia
}

Copyright $\odot 2018$ by authors, all rights reserved. Authors agree that this article remains permanently open access under the terms of the Creative Commons Attribution License 4.0 International License

\begin{abstract}
The objectives of this study were to determine the knowledge and attitude toward STI prevention, and actual situation of infections (chlamydia and gonorrhea infections) among out-of-school youth in the Philippines. As many as 129 out-of-school youth age 13-20 years old were participated in this study in September 2017. A self-administered questionnaire was used to assess characteristics, knowledge of STIs; sexual behavior; counselors for sexual problems; access to the internet; concerns about STIs; coping with STI symptoms using the scenario setting; sexual risks for STIs; and opinion. The presence or absence of chlamydia and gonorrhea infections in urine was determined with using Aptima Combo 2 Assay. Data was analyzed statistically with using mean, standard deviation, percentage, Mann-Whitney U, and Chi-square. p Value of $<0.05$ were considered statistically significant. The subjects were concerned about STI and had basic knowledge toward STI prevention but negative attitude toward safer sex. On the urine test, ten out of 126 participants (7.9\%) had positive reactions about chlamydia and three of them were co-infection with gonorrhea. Female participants were much more likely to get infected $(12.8 \%)$ than male (3.2\%). In conclusion, the knowledge toward STI prevention had no correlation with their attitude. Therefore, sexual education is not enough to focus on STI knowledge but also put more emphasis on practice to promote safer sexual behavior.
\end{abstract}

Keywords STIs, Prevention, Out-of-school Youth, Scale, Philippines

\section{Introduction}

The incidence of sexually transmitted infection (STI) among young individuals in the Philippines is increasing $[1,2]$; this results in serious reproductive health problems in young people throughout their lifetime. Poverty, religion, as well as insufficient sexual education and laws are considered some of the associated factors. Dropping out is also associated with a much higher risk of STI contraction for females. [3]

The number of children and out-of-school youth (OSY) in the Philippines is increasing. [4] Based on the 2017 Annual Poverty Indicators Survey (APIS), about nine percent of the estimated 39.2 million Filipinos aged 6 to 24 years old were out-of-school. [5] There are more than 3,000 OSY in Muntinlupa city. The Muntinlupa health center provides health services for young individuals through adolescent programs on sexual education, including on STI prevention. However, the incidence rate of STIs is continually increasing in their community. Some of the reasons for dropping out of school are marriage, in $32.6 \%$ of women, and poverty in $22.7 \%$ of men. Specifically, 1 in ten women aged $15-19$ years who dropped out from school had given birth, and $40 \%$ were not educated. [6] Lack of education may prevent them from seeking information, particularly about STI prevention, from health centers and schools and put them at high risk of acquiring STIs. However, there is lack of reports demonstrating the knowledge and attitudes toward STI prevention and the association with the prevalence of STIs among OSY in the Philippines. 
Therefore, this study aimed at examining the current incidence rate of STIs (chlamydia and gonorrhea infection) and current knowledge and attitude toward STI prevention and whether the knowledge and behavior toward STI prevention affected the risky behavior among OSY in Muntinlupa, Philippines.

\section{Materials and Methods}

\subsection{Materials}

We recruited 200 OSY aged from 13 to 20 in Poblacion, Muntinlupa, Manila. Number of samples was calculated based on the following formula.

$$
\mathrm{n}=\frac{\mathrm{N}}{1+\left(\mathrm{N}+\mathrm{e}^{2}\right)}
$$

The participants were chosen using simple random sampling from total number of the students (200 OSY) with their name list. Finally, we obtained informed consent from 129 participants (64.5\% response rate), and the number of valid response was 126 students $(97.7 \%$ valid response rate).

\subsection{Methods}

\subsubsection{Study Design}

It was a cross sectional study conducted in 2017 and focused on Muntinlupa city, Manila. The design of research was a quantitative research and the data collection of this research was implemented in September 2017 in Muntinlupa, Manila.

\subsubsection{Study Population}

The participants were OSY aged $13-20$ years who dropped out from school or did not finish school (including elementary school). They live in a town in Muntinlupa. A health center acquired a list of OSY compiled by barangay health workers and called for the recruitment of the research participants, with permission from their guardians. Those with mental illnesses and disabilities were excluded.

\subsubsection{Questionnaires}

An anonymous self-administered questionnaire was distributed to the participants. The questionnaire includes data on personal information (sex, age, educational status and level, and current occupation); knowledge of STIs (knowledge and understanding prevention of STIs in general, and HIV/AIDS); sexual behavior; counselors for sexual problems; access to the internet; concerns about STIs; coping with STI symptoms using the scenario setting; sexual risks for STIs; and opinions. The knowledge test for STIs had 14 questions, and maximum of 14 points can be obtained. With regards to coping with the symptoms of STIs, two kinds of scenarios that involve the symptoms of chlamydia and gonorrhea, which had different pathophysiology, were prepared, and the participants were asked with this question: "if these symptoms occurred, how do you cope with them?” The sexual risks for STIs were evaluated using the sexual risk scale (SRS). [7] This is a 38-item scale comprised of 6 subscales that measure the following: attitudes about safer sex, normative beliefs, intentions to practice safer sex, expectations about the feasibility of safer sex, perceived susceptibility of acquiring HIV/AIDS, and substance abuse. Responses were measured on a 5-point Likert-type scale (strongly disagree $=1$, disagree $=2$, neutral $=3$, agree $=4$, strongly agree=5). A low score based on the sexual risk scale is an indicator of an increased sexual risk. We used the Tagalog version of the questionnaires, which were translated based on the English version by a doctor in the city health department of Muntinlupa.

\subsubsection{Urine Test for Chlamydia and Gonorrhea}

For the detection of chlamydia and gonorrhea, the urine samples of 126 OSY (79 males and 47 females) were collected and tested using the Aptima Combo 2 Assay.

\subsubsection{Statistical Analysis}

SPSS Statistics version 22.0 software was used for statistical analysis. The Mann - Whitney U test was used to test the differences between the scores of the knowledge test for STIs and the presence or the results of urine test; and between counselor about sexual problems and age. The scorings of the knowledge test were presented as means and standard deviations. A Chi-square test was used to test the differences between sex and the results of urine test; between educational status and the results of urine test; between concern about STIs and the results of urine test; and between counselors for sexual problems and the results of urine test. In all cases, $\mathrm{p}$ values of $<0.05$ were considered statistically significant.

\subsubsection{Ethical Consideration}

This survey was approved by the mayor, city health officer of the department of health in Muntinlupa, and the ethical committee of Kobe University Graduate School of Health Sciences (no. 654) and University of the Philippines Manila. Before the start of the study, we explained the purpose and methods to the participants. Informed consent and approval were obtained from the participants and their parents, respectively. The participants answered the questionnaire and approved the urine test.

\section{Results}

\subsection{Characteristics and Sexual Behaviors}

Table 1 shows the characteristics of the subjects, of which 79 (62.7\%) were men. The mean age was $16.5 \pm 1.9$ (range: 13-20) years. 
Table 1. Characteristics of the participants

\begin{tabular}{|c|c|}
\hline Characteristics & n (\%) \\
\hline \multicolumn{2}{|l|}{ Sex } \\
\hline Male & $79(62.7 \%)$ \\
\hline Female & 47 (37.3\%) \\
\hline Age (years) $16.5 \pm 1.9$ & Mean \pm SD \\
\hline $1318(14.3 \%)$ & $1726(20.6 \%)$ \\
\hline $14 \quad 11(8.7 \%)$ & $1835(27.8 \%)$ \\
\hline $156(4.8 \%)$ & $196(4.8 \%)$ \\
\hline $1623(18.3 \%)$ & $20 \quad 1(0.8 \%)$ \\
\hline \multicolumn{2}{|l|}{ Educational status } \\
\hline Attending ALS & 27 (22.5\%) \\
\hline Stopped attending school & 93 (77.5\%) \\
\hline \multicolumn{2}{|l|}{ Educational level } \\
\hline Elementary school & $13(15.9 \%)$ \\
\hline Elementary school graduate & 69 (84.1\%) \\
\hline \multicolumn{2}{|l|}{ Work } \\
\hline Not working & $106(96.4 \%)$ \\
\hline Working & $4(3.6 \%)$ \\
\hline \multicolumn{2}{|l|}{ Counselors for sexual problems } \\
\hline Parents & 70 (59.7\%) \\
\hline Friends & $34(28.6 \%)$ \\
\hline Specialists (Dr, Nr) & $18(15.1 \%)$ \\
\hline Nobody & $9(7.6 \%)$ \\
\hline Relatives & $6(5.0 \%)$ \\
\hline Siblings & $4(3.4 \%)$ \\
\hline
\end{tabular}

With regards to educational status, $22.5 \%$ of the OSY attend the alternative learning system (ALS), which is a parallel learning system in the Philippines that provides a practical alternative to the existing formal instruction for those who cannot access formal education in schools. The rest of the OSY did not attend school at all, and among them, $15.9 \%$ stopped attending before graduating elementary school. Four subjects had work, and all of them were men.

With regards to the question on counselors for sexual concerns, three highest rates at which the OSY selected were "parents," "friends," and "specialists [doctors (Dr) or nurses (Nr)],” (59.7\%, 28.6\%, 15.1\%, respectively).

\subsection{Knowledge Test for STI Prevention}

The results of the knowledge test for STI prevention are shown in Table 2. More than $90 \%$ of the participants selected corrected answers to "It is important to maintain a healthy lifestyle for prevention of cervical cancer," "Having multiple sex partners is a risk factor for STI," and "You need to undergo a medical examination, if you have any symptoms of itchiness in, pain in and smell from your sex organ." On the other hand, 59.0\% selected correct answers to "Some STIs are asymptomatic," and 24.8\% selected to "STI symptoms in females are stronger than those in males.” The mean total score was 10.7 \pm 2.3 .

No significant differences were observed between the 2 groups in terms of the knowledge test score for STI prevention (men and women; attending ALS and stopped school; data not shown).

\subsection{Attitude toward Safer Sex}

Table 3 shows the scores of the sexual risk scale (SRS). The average total score was $103.3 \pm 33.0$ and each score of the subscales are shown in Table 3. No statistically significant differences were observed in terms of age, educational status, and the result of the urine test, except for educational level. (data not shown)

The OSY who stopped attending elementary school had a significantly lower score $(79.1 \pm 42.6)$ than those who completed elementary school $(108.5 \pm 28.7)$. $(\mathrm{p}<0.05)$ In addition, no correlation was observed in terms of the knowledge test and SRS scores. 
Table 2. Score of the knowledge test for STIs ( $n=117)$

\begin{tabular}{|c|c|c|}
\hline & Knowledge of STIs & Accuracy \\
\hline 1) & Sexually transmitted infections (STIs) are transmitted through sexual intercourse. & $96(82.1 \%)$ \\
\hline 2) & Some STIs are asymptomatic. & $69(59.0 \%)$ \\
\hline 3) & The symptoms of STIs in women are more unusual than those in men. & $29(24.8 \%)$ \\
\hline 4) & STI is a cause of abortion. & $71(60.7 \%)$ \\
\hline 5) & Some STIs are transmitted from mother to child. & $76(65.0 \%)$ \\
\hline 6) & Human papillomavirus (HPV) is the cause of cervical cancer. & $93(79.5 \%)$ \\
\hline 7) & Individuals who acquire STIs, such as chlamydia, $2-5$ times more likely to be HIV-positive. & $93(79.5 \%)$ \\
\hline 8) & AIDS is a STI. & $86(72.5 \%)$ \\
\hline 9) & It is important to maintain a healthy lifestyle (good nutrition and sleeping habits) to prevent cervical cancer. & $108(92.3 \%)$ \\
\hline 10) & Condoms are effective in preventing STIs. & $104(88.9 \%)$ \\
\hline 11) & Substance abuse (smoking, drug use, or alcohol consumption) increases the chances of risky sex. & $95(81.2 \%)$ \\
\hline 12) & Individuals who engage in anal and oral sex have a higher risk of transmitting STIs. & $99(84.6 \%)$ \\
\hline 13) & Having multiple sex partners is a risk factor for STIs. & $106(90.7 \%)$ \\
\hline \multirow[t]{2}{*}{ 14) } & $\begin{array}{l}\text { Individuals must undergo medical examinations if any of the following symptoms are present: itchiness, pain, and } \\
\text { foul smell in the sex organ. }\end{array}$ & $111(94.9 \%)$ \\
\hline & Average score \pm SD & $10.7 \pm 2.3$ \\
\hline
\end{tabular}

Table 3. Scores of the sexual-risk scale $(n=126)$

\begin{tabular}{cc}
\hline Item & Mean \pm SD \\
\hline Total & $103.3 \pm 33.0$ \\
Attitude & $36.0 \pm 12.8$ \\
Peer norms & $17.2 \pm 7.0$ \\
Susceptibility & $12.3 \pm 4.4$ \\
Substance use & $5.0 \pm 2.4$ \\
Intentions & $18.9 \pm 7.8$ \\
Expectations & $14.0 \pm 5.0$ \\
\hline
\end{tabular}

\subsection{Practices toward Coping with STI Symptoms}

Based on the results of the scenario setting on coping with the STI symptoms, $71.1 \%$ of the participants agree to undergo medical examination if chlamydia symptoms were present, and $80.4 \%$ agree in the case of gonorrhea. With regards to proportion of OSY who chose appropriate answers for chlamydia symptoms, the rate of correct answers in the group attending ALS was significantly higher than that in the group that do go to school $(\mathrm{p}<0.05)$. Meanwhile, the differences in the urine test results between the positive group and negative group based on the results of urine test were not significant.

\subsection{Urine Test Results Indicating Chlamydia and Gonorrhea}

Table 4 shows the urine test results of the positive and negative groups. Among participants, 10 (7.9\%) were STIs positive. Three (2.4\%) out of these 10 were coinfected with gonorrhea and chlamydia. The rest of seven were only positive for chlamydia. Although there was no statistically significant difference among the male and female participants in terms of infection rate, the proportion of female OSY who tested positive was 4 times higher than that of male OSY. The age distributions of participants who were diagnosed STIs positive were $10 \%(n=1)$ in the group aged 13-15 years old and $90 \%(n=9)$ in the group aged 16-20 years old. In the positive group, no participants attended the ALS, and all of them completely stopped attending schools. Around $72.4 \%$ of the participants reported that they have concerns about STIs, and the proportions in both the positive and negative groups were similar. With regards to the counselor for sexual problems, the number of OSY who chose their friends as counselor is significantly higher in the positive group than in the negative group. The mean scores of the knowledge test for STI prevention were $10.6 \pm 2.3$ and $10.7 \pm 1.8$ in the positive group and negative group, respectively.

\subsection{Associations among the Counselors for Sexual Problems and Age and Specific Counselors and Educational Status}

Table 5 shows the mean age of participants who chose their parents as counselor was significantly lower than 
those who did not choose their parents $(\mathrm{p}<0.05)$. On the other hand, the mean ages of the participants who reported their friends as counselor and those who have no one to consult were significantly higher $(\mathrm{p}<0.001)$.
Only 52.8\% of the participants stopped attending school and chose their parents as counselor, which was significantly lower than that of the group that attends ALS $(\mathrm{p}<0.001)$.

Table 4. Correlation between the results of urine test and other factors

\begin{tabular}{|c|c|c|c|c|}
\hline & Positive & Negative & Total & $\mathrm{p}$ \\
\hline \multicolumn{5}{|l|}{ Urine test } \\
\hline chlamydia & \multicolumn{4}{|l|}{$10(7.9 \%)$} \\
\hline gonorrhea & \multicolumn{4}{|l|}{$3(2.4 \%)$} \\
\hline \multicolumn{5}{|l|}{ Sex } \\
\hline Male & $4(3.2 \%)$ & $75(96.8 \%)$ & 79 & \multirow{2}{*}{0.122} \\
\hline Female & $6(12.8 \%)$ & $41(87.2 \%)$ & 47 & \\
\hline \multicolumn{5}{|l|}{ Age } \\
\hline $13-15$ & $1(10.0 \%)$ & $34(29.3 \%)$ & 35 (27.8\%) & \\
\hline $16-20$ & $9(90.0 \%)$ & $82(70.7 \%)$ & $91(72.2 \%)$ & \\
\hline \multicolumn{5}{|l|}{ Educational status } \\
\hline Attending ALS & $0(0.0 \%)$ & $27(24.3 \%)$ & 27 (22.5\%) & \multirow{2}{*}{0.09} \\
\hline Stopped attending school & $9(100.0 \%)$ & $84(75.7 \%)$ & $93(77.5 \%)$ & \\
\hline \multicolumn{5}{|l|}{ Concern about STIs } \\
\hline Yes & $8(80 \%)$ & $76(71.7 \%)$ & $84(72.4 \%)$ & \multirow{2}{*}{0.57} \\
\hline No & $2(20 \%)$ & $30(28.3 \%)$ & $32(27.6 \%)$ & \\
\hline \multicolumn{5}{|l|}{ Counselors for sexual problems } \\
\hline Parents & $5(50.0 \%)$ & $65(60.6 \%)$ & $70(59.7 \%)$ & 0.52 \\
\hline Siblings & $1(10.0 \%)$ & $3(2.8 \%)$ & $4(3.4 \%)$ & 0.22 \\
\hline Relatives & $0(0 \%)$ & $6(5.5 \%)$ & $6(5.0 \%)$ & 0.45 \\
\hline Neighbors & $0(0 \%)$ & $1(0.9 \%)$ & $1(0.80 \%)$ & 0.76 \\
\hline Friends & $6(60.0 \%)$ & $28(25.7 \%)$ & $34(28.6 \%)$ & $0.02 *$ \\
\hline Teachers & $0(0 \%)$ & $1(0.9 \%)$ & $1(0.80 \%)$ & 0.76 \\
\hline Specialists (Dr, Nr) & $1(10.0 \%)$ & $17(15.6 \%)$ & $18(15.1 \%)$ & 0.64 \\
\hline H)-Others & $1(10.0 \%)$ & $1(0.9 \%)$ & $2(1.7 \%)$ & $0.032 *$ \\
\hline H) Nobody & $1(10.0 \%)$ & $8(7.3 \%)$ & $9(7.6 \%)$ & 0.76 \\
\hline \multicolumn{5}{|c|}{ Score of the knowledge test for STIs } \\
\hline Mean \pm SD & $10.6 \pm 2.3$ & $10.7 \pm 1.8$ & $10.7 \pm 2.3$ & \\
\hline
\end{tabular}

${ }^{*} \mathrm{p}<0.05$

Table 5. Relationships between counselor about sexual problems and other components

\begin{tabular}{|c|c|c|}
\hline & \multicolumn{2}{|c|}{ Age } \\
\hline & Mean \pm SD & $\mathrm{p}$ \\
\hline Parents (n=71) & $16.0 \pm 1.9$ & $0.030 *$ \\
\hline Siblings $(n=4)$ & $17.50 \pm 1.0$ & 0.21 \\
\hline Relatives $(n=6)$ & $16.7 \pm 0.82$ & 0.38 \\
\hline Neighbors $(\mathrm{n}=1)$ & - & - \\
\hline Friends ( $n=34)$ & $17.1 \pm 1.2$ & $0.00 * *$ \\
\hline Teachers $(\mathrm{n}=1)$ & - & - \\
\hline Specialists $(\mathrm{Dr}, \mathrm{Nr})(\mathrm{n}=18)$ & $15.9 \pm 2.0$ & 0.33 \\
\hline Others $(n=2)$ & $18.0 \pm 0$ & $0.00^{* *}$ \\
\hline Nobody $(n=9)$ & $18.2 \pm 1.1$ & $0.00 * *$ \\
\hline Total $(n=119)$ & & \\
\hline
\end{tabular}

${ }^{*} \mathrm{p}<0.05, * * \mathrm{p}<0.005$ 


\section{Discussion}

This is the first study that assessed the knowledge and attitude of OSY toward STI prevention, and their association with the incidence rate of STIs (chlamydia and gonorrhea) and risky sexual behavior among OSY in the Philippines. Although the participants have moderate knowledge of STIs, their attitudes toward safer sex were not sufficient. In addition, the relatively high prevalence of STIs suggests that they engage in risky sexual behavior and acquiring STIs is an outcome of their attitude toward safer sex.

OSY in the Philippines have moderate knowledge of STI prevention. However, the attitude toward safer sex was considerably low. In a study that targeted university and high school students in Japan, the scores were 137.2 14.18 and 133.1 \pm 14.60 , respectively. [8] The scores of each subscale in the present study were lower than those in other studies. $[9,10]$ This result indicates that this group is at high risk for STIs.

With regards to STIs, those who stopped attending primary schools, those who did not choose their parents as counselor, and those who consulted their friends are particularly considered as the high-risk groups. The common factor among these participants is the lack of education. In this study, education seems to influence two facts: 1) they have limited choices for the counselor and 2) they tend to have a lower responsibility for their attitude and behavior. These factors attributed to the fact that they do not have a means to obtain accurate information, and they also feel powerless. With regards to powerlessness, since attitude problem is associated with STIs, it is obvious that young individuals who do not have access to education, whether formal or not, are at high-risk for infection because education contributes to human capital by developing a range of skills and traits, such as cognitive skills, problem solving ability, learned effectiveness, and personal control. [11] Ultimately, these facts have influences on STIs.

Approximately $7.9 \%$ of the participants were infected based on the urine test. The proportion of women who were infected was relatively higher than those of men. This indicates that female OSY are more vulnerable than male OSY, and we need to obtain detailed information about their surrounding environment. Moreover, in this study the infection rate of chlamydia in women was $12.8 \%$, which was higher than that in young women in other countries. $[12,13]$

Additional information regarding a participant who was positive for a STI can be obtained. The minimum age of the participants who acquired STIs was 14 years. Since the average age of sexual debut is 18 years old in the Philippines, STIs at the age of 14 must be taken into consideration. [14] The females who had sexual debut at the aged of 14 or below had experienced significantly more sexual abuse than the females with a later debut.
[15] In addition, STIs in children under 13-14 years may indicate child sexual abuse. [16] The peak age of being sexual abused was $11-20$ years and over $60 \%$ of the women who had sexual abuse were children and teenagers. [17] Early debut was positively correlated with risky behaviors, such as the number of partners, experience of oral and anal sex, health behaviors, such as smoking, drug and alcohol use, and antisocial behavior, such as being violent, lying, stealing and running away from home. [15] Therefore, STIs at the age of 14 suggests the possibility of child sexual abuse, and thus, the history of the infection must be further examined.

Knowledge of STI prevention in young individuals who are attending school and, the interventions that support appropriate sexual practices are important.

\section{Conclusions}

The OSY in the Philippines have basic knowledge of STIs. However, the attitudes toward safer sex were considerably low. The relatively high prevalence of STIs suggests that OSY may engage in risky sexual behaviors, and this can be attributed to the negative attitude toward safer sex. Thus, the OSY must be knowledgeable not only in the prevention of STIs but also in the interventions that support appropriate sexual practices. Moreover, further studies that obtain detailed information on those who acquired STIs must be conducted. In addition, this study encouraged improvement of effective sexual education and STI prevention to include not only STI knowledge but also practical contents such as how to use condom or where to consult when STIs symptoms occur among OSY as well as in-school youth in the Philippines.

\section{Acknowledgements}

We wish to express our appreciation to the research participants (the OSY and their parents); the Mayor of Muntinlupa city and the barangay health workers involved in the present study. And we would like to gratefully acknowledge Dr. Dana D. Dehart on the utilization the sexual risks scale. We wish to acknowledge the support of staff of The City Health Department of Muntinlupa and Southville 3 health center throughout this study.

\section{REFERENCES}

[1] WHO. Sexual and Reproductive Health of Adolescents and Youths in the Philippines [serial online]. 2005. Online Available: http://iris.wpro.who.int/bitstream/handle/10665. 1/5513/9290611898_eng.pdf.

[2] A. Reddy, K.C.W. Htin, Y.Y. Shwe. HIV and AIDS Data 
Hub for Asia Pacific: a regional tool to support strategic information needs, Western Pacific Surveillance and Response Journal, Vol.3, No.3, 2012

[3] D. M. Anderson, C. C. Portner, High school dropouts and sexually transmitted infections, South Econ J, Vol. 81, No. 1, 113-134, 2014.

[4] Philippines Statistic Authority, Out-of-School Children and Youth in the Philippines (Results from the 2013 Functional Literacy, Education and Mass Media Survey), 2013. Online Available:

https://psa.gov.ph/content/out-school-children-and-youth-p hilippines-results-2013-functional-literacy-education-and.

[5] Nine Percent of Filipinos Aged 6 to 24 years are Out of School (Results from the 2017 Annual Poverty Indicators Survey), 2017. Online Available: https://psa.gov.ph/conten t/nine-percent-filipinos-aged-6-24-years-are-out-school-res ults-2017-annual-poverty-indicators

[6] Philippine Statics Authority, One in Ten Young Filipino Women Age 15 to 19 Is Already A Mother or Pregnant With First Child (Final Results from the 2013 National Demographic and Health Survey), 2013. Online Available: https://psa.gov.ph/content/one-ten-young-filipino-womenage-15-19-already-mother-or-pregnant-first-child-final-res ults.

[7] D.D. DeHart, J.C. Birkimer, Trying to practice safer sex: Development of the sexual risks scale, Journal of Sex Research, Vol.34, No.1, 11-25, 1997.

[8] Y. Tanaka, R. Okamoto, The Development and Study of the Reliability and Validity of a Japanese Version of the Sexual Risks Scale with a Focus on the Intention to Try Safer Sex Practices, Japanese Journal of school health, Vol.50, No.186, 186-195, 2008.

[9] N. Villegas, D. Santisteban, R. Cianelli, L. Ferrer, T. Ambrosia, N. Peragallo, L. Lara, Pilot Testing an Internet Based STI and HIV Prevention Intervention With Chilean Women. Journal of Nursing Scholarship, Vol.47, No.2, 106-116, 2015.
[10] D. N. Hawthorne, An effectiveness study of the UCLA Friendship and Intimacy module, Doctoral dissertation, Rutgers the States University of New Jersey, Graduate School of Applied and Professional Psychology, 2013.

[11] J. Mirowsky, C. E. Ross. Education, learned effectiveness and health. London Review of Education, Vol.3, No.3, 205-220, 2005.

[12] A. I. Obasi, R. Balira, J. Todd, D. A. Ross, J. Changalucha, F. Mosha, H. Grosskurth, R. Peeling, D. C. W. Mabey, R. J. Hayes, Prevalence of HIV and Chlamydia trachomatis infection in 15-19 - year olds in rural Tanzania, Tropical medicine \& international health, Vol.6, No.7, 517-525, 2001.

[13] V.M. Pinto, C.L. Szwarcwald, C. Baroni, L.L. Stringari, L.A. Inocêncio, A.E. Miranda, Chlamydia trachomatis prevalence and risk behaviors in parturient women aged 15 to 24 in Brazil, Sexually transmitted diseases, Vol.38, No.10, 957-961, 2011.

[14] WHO. Sexual and reproductive health of adolescents and youths in Philippines: a review of literature and projects, 1995-2003. 2005. Online Available: http://www.wpro.who .int/publications/docs/ASRHkorea.pdf

[15] Å. A. Kastbom, G. Sydsjö, M. Bladh, G. Priebe, C. G. Svedin, Sexual debut before the age of 14 leads to poorer psychosocial health and risky behaviour in later life, Acta Paediatrica, Vol. 104, No. 1, 91-100, 2015.

[16] K. E. Rogstad, D. Wilkinson, A. Robinson, Sexually transmitted infections in children as a marker of child sexual abuse and direction of future research, Current opinion in infectious diseases, Vol. 29, No. 1, 41-44, 2016.

[17] B. C. Acebes - Escobal, M. C. Nerida, R. A. Chez, Abuse of women and children in a Philippine community, International Journal of Gynecology \& Obstetrics, Vol. 76, No. 2, 213-217, 2002. 